\title{
Characterization of blood dendritic and regulatory T cells in asymptomatic adults with sub-microscopic Plasmodium falciparum or Plasmodium vivax infection
}

Steven Kho ${ }^{1 *}$, Jutta Marfurt ${ }^{1}$, Irene Handayuni ${ }^{1}$, Zuleima Pava ${ }^{1}$, Rintis Noviyanti ${ }^{2}$, Andreas Kusuma ${ }^{2}$, Kim A. Piera' ${ }^{1}$, Faustina H. Burdam³ ${ }^{3}$ Enny Kenangalem ${ }^{3,4}$, Daniel A. Lampah³, Christian R. Engwerda ${ }^{5}$, Jeanne R. Poespoprodjo ${ }^{3,4,6}$, Ric N. Price ${ }^{1,7}$, Nicholas M. Anstey ${ }^{1}$, Gabriela Minigo ${ }^{1 \dagger}$ and Tonia Woodberry ${ }^{1 \dagger}$

\begin{abstract}
Background: Plasmodium falciparum and Plasmodium vivax infections compromise dendritic cell (DC) function and expand regulatory $T$ (Treg) cells in both clinical disease (malaria) and experimental human sub-microscopic infection. Conversely, in asymptomatic microscopy-positive (patent) P. falciparum or P. vivax infection in endemic areas, blood DC increase or retain HLA-DR expression and Treg cells exhibit reduced activation, suggesting that DC and Treg cells contribute to the control of patent asymptomatic infection. The effect of sub-microscopic (sub-patent) asymptomatic Plasmodium infection on DC and Treg cells in malaria-endemic area residents remains unclear.

Methods: In a cross-sectional household survey conducted in Papua, Indonesia, 162 asymptomatic adults were prospectively evaluated for DC and Treg cells using field-based flow cytometry. Of these, 161 individuals (99\%) were assessed retrospectively by polymerase chain reaction (PCR), 19 of whom had sub-microscopic infection with $P$. falciparum and 15 with sub-microscopic $P$. vivax infection. Flow cytometric data were re-analysed after re-grouping asymptomatic individuals according to PCR results into negative controls, sub-microscopic and microscopic parasitaemia to examine DC and Treg cell phenotype in sub-microscopic infection.

Results: Asymptomatic adults with sub-microscopic P. falciparum or P. vivax infection had DC HLA-DR expression and Treg cell activation comparable to PCR-negative controls. Sub-microscopic P. falciparum infection was associated with lower peripheral $\mathrm{CD} 4^{+} \mathrm{T}$ cells and lymphocytes, however sub-microscopic Plasmodium infection had no apparent effect on DC sub-set number or Treg cell frequency.

Conclusions: In contrast to the impairment of DC maturation/function and the activation of Treg cells seen with sub-microscopic parasitaemia in primary experimental human Plasmodium infection, no phenotypic evidence of dysregulation of DC and Treg cells was observed in asymptomatic sub-microscopic Plasmodium infection in Indonesian adults. This is consistent with DC and Treg cells retaining their functional capacity in sub-microscopic asymptomatic infection with P. falciparum or P. vivax in malaria-endemic areas.
\end{abstract}

Keywords: Malaria, Clinical immunity, Dendritic cell, Regulatory T cell, Asymptomatic, Sub-microscopic, Adults, Vivax, Falciparum, Human

\footnotetext{
*Correspondence: steven.kho@menzies.edu.au

${ }^{\dagger}$ Gabriela Minigo and Tonia Woodberry contributed equally to this work

${ }^{1}$ Global and Tropical Health Division, Menzies School of Health Research

and Charles Darwin University, Darwin, Australia

Full list of author information is available at the end of the article
} 


\section{Background}

A significant proportion of individuals living in areas where malaria is endemic have Plasmodium parasitaemia without the presence of symptoms. This is thought to reflect either the early stages of infection or the acquisition of clinical immunity that restricts parasite expansion and prevents clinical disease [1,2]. Microscopy or rapid diagnostic tests remain the most common method for the diagnosis of Plasmodium infection. However, it is now recognized that even in low-transmission settings a large proportion of microscopy-negative individuals have sub-microscopic parasitaemia identified by polymerase chain reaction (PCR) [3-7]. These sub-microscopic infections frequently remain undetected and untreated and hence, contribute significantly to the transmittable reservoir and potentially to morbidity [8]. Sensitive molecular techniques are now used increasingly in epidemiological studies to detect sub-microscopic infection with limits of detection below 0.1 parasites per $\mu \mathrm{l}$ [9-12]. Sub-microscopic Plasmodium infections are important and warrant consideration in malaria intervention and elimination programmes $[9,13]$.

While immune correlates in microscopy-positive asymptomatic parasitaemia have been reported [14-17], few data exist on immune regulation at very low parasitaemia, with no data available on the dendritic cell (DC) and regulatory $\mathrm{T}$ (Treg) cell response at sub-microscopic levels of infection in malaria-endemic areas. In individuals hospitalized with clinical disease from Plasmodium falciparum and Plasmodium vivax, blood DC are functionally and numerically compromised [18, 19] while Treg cells expand $[20,21]$, promoting immune suppression. Similarly, in low-dose experimental $P$. falciparum blood-stage infection of naïve volunteers, blood DC become non-functional and apoptose at PCR-level parasitaemia below the detection limit of microscopy [22, 23]. In contrast, the recent demonstration that adults and children with asymptomatic microscopy-positive $P$. falciparum or $P$. vivax infection have increased or retained activation of blood DC and reduced activation of Treg cells [14], suggests that appropriate DC maturation and less Treg suppression may contribute to the active control of asymptomatic infection. Therefore, in contrast to naïve individuals with sub-microscopic infection, it is hypothesized that asymptomatic-exposed individuals with sub-microscopic infection respond similarly to patent asymptomatic-exposed individuals, such that DC remain functional while Treg cells display reduced suppressive function.

In a previous publication [14], parasitaemia in asymptomatic adults was evaluated by microscopy only. Using $\mathrm{PCR}$, a large proportion of microscopy-negative controls were subsequently identified as having sub-microscopic Plasmodium infection. In an extension of the original study [14], flow cytometry data were re-categorized in adults using the additional PCR results. Sub-microscopic infection with $P$. falciparum or $P$. vivax was identified from microscopy-negative controls and then compared to patent infection and acute malaria. The results indicate that while peripheral $\mathrm{CD} 4^{+} \mathrm{T}$ cells decline, blood $\mathrm{DC}$ and Treg cells remain numerically and phenotypically, functionally preserved during asymptomatic sub-microscopic $P$. falciparum or $P$. vivax infection.

\section{Methods}

\section{Study participants and sample collection}

The field study was conducted in Timika, in Papua, Indonesia, a region with high but unstable malaria transmission [24]. Participants were enrolled and sampled as part of a household survey conducted in 2013, as previously reported [14]. Briefly, 162 Papuan and non-Papuan adults had venous blood taken, were diagnosed for Plasmodium infection by microscopy, and were evaluated by field-based flow cytometry of peripheral blood for DC and Treg cells [14]. All participants were asymptomatic with no documented fever $\left(<37{ }^{\circ} \mathrm{C}\right)$, or other symptoms of malaria at recruitment or within the preceding $24 \mathrm{~h}$. Participants with detectable parasitaemia by microscopy were treated with dihydroartemisinin-piperaquine according to local protocols. Approximately $200 \mu \mathrm{l}$ of packed red blood cells (RBCs) were frozen per adult to verify patent infections and identify sub-microscopic Plasmodium infections by PCR. As a comparator group, 14 adults being treated for acute uncomplicated malaria at Rumah Sakit Mitra Masyarakat (RSMM) hospital in Timika were enrolled as described previously [14].

\section{Identification of sub-microscopic infection}

Frozen RBCs were transferred to the Eijkman Institute for Molecular Biology in Jakarta for molecular analysis. The QIAamp 96 DNA Blood Kit (Qiagen) was used according to manufacturer's instructions to extract genomic DNA from $>50 \mu \mathrm{l}$ of RBCs. Gene target amplification for $P$. falciparum, P. vivax, Plasmodium malariae, and Plasmodium ovale speciation was performed on a Veriti $96-\mathrm{W}$ thermal cycler (Thermo Fisher Scientific) using a nested PCR approach as described elsewhere [25]. The limit of detection of the assay was 0.2 parasites per $\mu \mathrm{l}$ as evaluated using well-characterized samples of $P$. falciparum and $P$. vivax (unpublished observations: Piera et al.). Positive results reflected live parasites, with previous clinical and human challenge studies showing that dead or dying parasites are cleared within one to 3 days of anti-malarial treatment $[26,27]$. 


\section{Whole blood flow cytometry}

DC and Treg cells were identified by fresh whole blood flow cytometry using protocols detailed previously [14]. DC and Treg antibody panels are listed in Additional file 1. All samples were acquired on a portable BD Accuri C6 flow cytometer using CFlow Sampler Software (BD Biosciences). All antibodies were purchased from BioLegend (San Diego, CA, USA).

\section{Data analysis}

Asymptomatic individuals were categorized into submicroscopic or patent infection according to microscopy and PCR results. Individuals that were both microscopyand PCR-negative were considered uninfected controls. Those that were microscopy-negative and PCR-positive were categorized as sub-microscopic infections. Microscopy-positive individuals were considered as patent infections regardless of their PCR results. Flow cytometric data were analysed on FlowJo (TreeStar, Ashland, OR, USA) and absolute calculations performed as described elsewhere [14]. DC and Treg cell flow cytometry data from the same sample were only available in $41 \%$ of participants due to either constraints in the amount of blood available for testing, or loss of sample quality due to insufficient lysis of RBCs during processing. Samples with fewer than 20 events in the DC sub-set gates were excluded. All statistical analyses were conducted using GraphPad Prism 6 (GraphPad Software, La Jolla, CA, USA). The Kruskal-Wallis test with Dunn's multiple comparisons test, or the Mann-Whitney $U$ test was used for statistical comparison as indicated.

\section{Ethics}

The study was approved by the Human Research Ethics Committees of Gadjah Mada University, Yogyakarta, Indonesia, the Eijkman Institute Research Ethics Commission, Jakarta, Indonesia, and the NT Department of Health and Families and Menzies School of Health Research, Darwin, Australia. Written informed consent was obtained from all participants (or the primary caregiver or relative) prior to blood sampling.

\section{Results}

\section{Study population}

Of the 162 asymptomatic adults that were originally sampled, 122 were microscopy-negative and 40 had patent infections. One microscopy-negative individual had no PCR data and was excluded. Thirty-one per cent (38/121) of the microscopy-negative adults had sub-microscopic infection with Plasmodium. Four sub-microscopic infections were excluded from analysis due to either mixed, or $P$. malariae sub-microscopic infection. A further four adults with mono-species infection by microscopy were excluded due to infection by multiple species at the sub-microscopic level. The remainder of 153 asymptomatic adults were included in this analysis, of whom 19 had sub-microscopic P. falciparum infection, 15 had sub-microscopic $P$. vivax infection, 17 had patent $P$. falciparum infection, and 19 had patent $P$. vivax infection. Fourteen adults with acute uncomplicated malaria diagnosed by microscopy were included for comparison.

Participant characteristics are summarized in Table 1. The majority of groups were gender balanced. Forty-eight per cent of adults $(80 / 153)$ were Papuan. All participants were resident in the Timika district, with $94 \%$ living in Timika for more than 2 years and $59 \%$ for more than 10 years. Of the 34 asymptomatic adults with sub-microscopic $P$. falciparum or $P$. vivax infection, $91 \%(31 / 34)$ had lived in Timika for more than 2 years and $56 \%$ (19/34) for more than 10 years. Asymptomatic adults with sub-microscopic $P$. falciparum infection had significantly reduced lymphocyte counts $(P=0.015)$ (Table 1$)$ [14]. There were no other significant differences in baseline characteristics between adults with asymptomatic sub-microscopic infections and controls.

\section{Peripheral DC HLA-DR expression and DC sub-set numbers are retained in asymptomatic sub-microscopic Plasmodium falciparum or Plasmodium vivax infection}

Total circulating DC was assessed in $54 \%$ (82/153) of participants and identified by flow cytometry as described elsewhere [14] (Additional file 2: Figure S1B). Total DC were defined as lineage marker-negative $\mathrm{HLA}-\mathrm{DR}^{+}$cells. The median fluorescent intensity (MFI) of HLA-DR expression was used as a measure of DC activation/maturation. In asymptomatic adults with sub-microscopic and patent $P$. falciparum or $P$. vivax infection, HLA-DR expression on total DC were comparable to controls (Fig. 1). Conversely, as previously reported, adults with acute uncomplicated $P$. falciparum or $P$. vivax malaria had significantly lower expression of HLA-DR on total DC when compared to controls (Fig. 1) [14].

Circulating DC sub-sets were assessed in $56 \%$ (86/153) of participants and reported as the absolute number of $\mathrm{CD}{ }^{+}{ }^{+}$(blood DC antigen 2 [BDCA-2] positive) plasmacytoid DC (pDC), CD1c ${ }^{+}$(BDCA-1 positive) $\mathrm{mDC}$ $\left(\mathrm{CD} 1 \mathrm{c}^{+} \mathrm{mDC}\right)$, and $\mathrm{CD} 141^{+}$(BDCA-3 positive) $\mathrm{mDC}$ $\left(\mathrm{CD} 141^{+} \mathrm{mDC}\right)$ as per flow cytometric gating of $\mathrm{DC}$ sub-sets [14] (Additional file 2: Figure S1A). The number of circulating $\mathrm{pDC}, \mathrm{CD} 1 \mathrm{c}^{+} \mathrm{mDC}$, and $\mathrm{CD} 141^{+} \mathrm{mDC}$ in asymptomatic adults with either sub-microscopic, or patent $P$. falciparum or $P$. vivax infection were not significantly different from controls (Fig. 2a-c). In contrast, as previously reported [14], $\mathrm{pDC}$ and $\mathrm{CD} 1 \mathrm{c}^{+} \mathrm{mDC}$ numbers were significantly reduced and $\mathrm{CD} 141^{+} \mathrm{mDC}$ were unchanged in adults with acute uncomplicated malaria 


\section{Table 1 Study participants}

\begin{tabular}{|c|c|c|c|c|c|c|c|}
\hline \multirow[t]{4}{*}{ Characteristics } & \multicolumn{7}{|c|}{ Values for indicated group [median (IQR)] or individual values } \\
\hline & \multirow[t]{3}{*}{ Control } & \multicolumn{4}{|l|}{ Asymptomatic } & \multicolumn{2}{|c|}{ Acute uncomplicated } \\
\hline & & Sub-microscopic & Sub-microscopic & Patent & Patent & Malaria & Malaria \\
\hline & & P. falciparum & P. vivax & P. falciparum & P. vivax & P. falciparum & P. vivax \\
\hline \multicolumn{8}{|l|}{ No. of subjects } \\
\hline Total & 83 & 19 & 15 & 17 & 19 & 6 & 8 \\
\hline Female/male & $46 / 37$ & $10 / 9$ & $8 / 7$ & $12 / 5$ & $14 / 5$ & $4 / 2$ & $5 / 3$ \\
\hline Papuan/non-Papuan & $29 / 54$ & $9 / 10$ & $9 / 6$ & $7 / 10$ & $14 / 5$ & $6 / 0$ & $6 / 2$ \\
\hline Age (years) & $30(25-37)$ & $31(26-36)$ & $28(21-31)$ & $28(24-36)$ & $32(30-36)$ & $21(20-24)^{*}$ & $27(23-36)$ \\
\hline $\begin{array}{l}\text { Time resident in area } \\
\text { (years) }\end{array}$ & $12(5-20)$ & $10(6-18)$ & $9(5-25)$ & $10(5-22)$ & $10(2-15)$ & NA & NA \\
\hline No. of parasites/ $\mu$ l & ND & ND & ND & $294(82-2065)$ & 210 (89-696) & $\begin{array}{l}24,725(10,734- \\
57,274)^{\#}\end{array}$ & $\begin{array}{l}58,341(10,778- \\
89,678)^{\#}\end{array}$ \\
\hline $\begin{array}{l}\text { Lymphocyte count } \\
\left(10^{9} / l\right)\end{array}$ & $2.5(2.2-3.1)$ & $2.2(1.5-2.6)^{\mathrm{a}}$ & $2.6(2.2-3.7)$ & $2.5(1.7-2.8)$ & $2.5(1.8-3.7)$ & $1.4(0.7-1.6)^{* *}$ & $1.0(0.7-1.2)^{* * *}$ \\
\hline $\begin{array}{l}\text { Monocyte count } \\
\left(10^{9} / l\right)\end{array}$ & $0.5(0.4-0.6)$ & $0.4(0.3-0.7)$ & $0.6(0.4-0.7)$ & $0.6(0.5-0.7)^{\mathrm{a}}$ & $0.5(0.3-0.8)$ & $0.7(0.6-0.7)^{*}$ & $0.9(0.4-1.4)^{\mathrm{a}}$ \\
\hline
\end{tabular}

IQR interquartile range, ND no parasite detected by microscopy, $N A$ data not available

Significantly different to control, Kruskal-Wallis test with Dunn's multiple comparisons

* $\mathrm{P}<0.05$

** $P<0.005$

*** $\mathrm{P}<0.0005$

\# Significantly different to species-matched patent infection, Kruskal-Wallis test with Dunn's multiple comparisons $(\mathrm{P}<0.0005)$

a Significantly different to control, Mann-Whitney $U$ test $(P<0.05)$

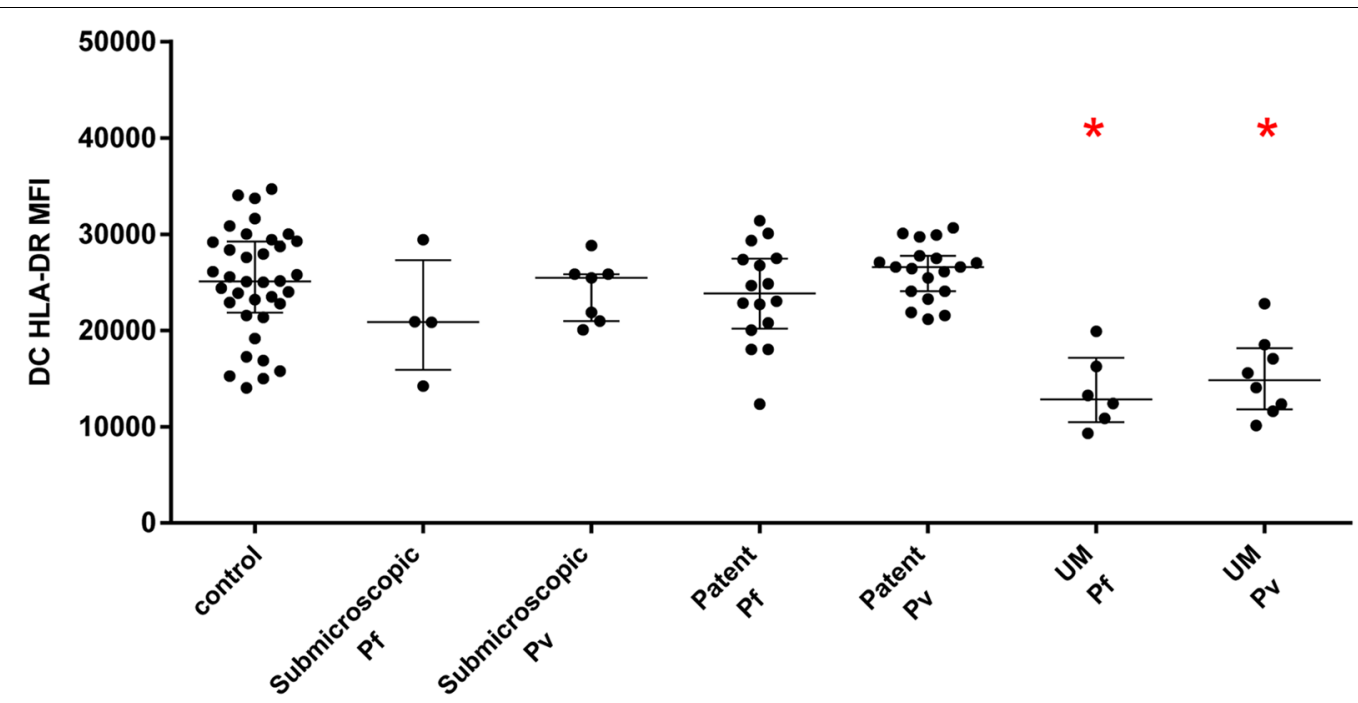

Fig. 1 HLA-DR MFI of total DC was determined in adult controls $(n=36)$, asymptomatic sub-microscopic P. falciparum (Pf) infection $(n=4)$, asymptomatic sub-microscopic $P$. vivax $(P v)$ infection $(n=7)$, asymptomatic patent $P$. falciparum infection $(n=16)$, asymptomatic patent $P$. vivax infection $(n=19)$, uncomplicated (UM) P. falciparum-infected adults $(n=6)$, and uncomplicated P. vivax-infected adults $(n=8)$. Graphs show median with interquartile range. Kruskal-Wallis test with Dunn's multiple comparisons test was used to compare between groups ( ${ }^{*}$ significantly different to control). Data were obtained by analysis of fresh whole blood using 4-colour flow cytometry panels 
(Fig. 2a-c). Patients with acute uncomplicated P. falciparum or $P$. vivax infection were analysed as a single group because of the low number of patients with DC sub-set data.

\section{Reduced $\mathrm{CD}^{+} \mathrm{T}$ cells and preservation of Treg cells in asymptomatic sub-microscopic Plasmodium infection}

Regulatory T cells were assessed in $84 \%(129 / 153)$ of participants and were identified by flow cytometry as $\mathrm{CD} 4^{+} \mathrm{CD} 25^{+} \mathrm{CD} 127^{\text {low }}$ lymphocytes, and sub-divided

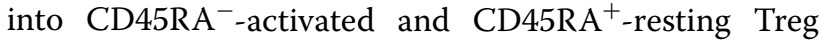
cells (aTreg and rTreg, respectively) as per flow cytometric gating [14] (Additional file 2: Figure S1C). In asymptomatic adults with sub-microscopic and patent $P$. falciparum or $P$. vivax infection, there were no changes in the absolute or relative number of Treg cells compared to controls (Table 2). In asymptomatic submicroscopic $P$. falciparum or $P$. vivax infection, the proportion of activated Treg cells (CD25 ${ }^{\text {high }}$ CD $45 \mathrm{RA}^{-}$) and rTreg-to-aTreg ratios were comparable to aparasitaemic controls (Table 2). This result differed from the previously reported lower proportion of activated Treg cells in asymptomatic adults with patent $P$. falciparum or $P$. vivax infection [14]. Asymptomatic adults with sub-microscopic $P$. falciparum infection exhibited reduced $\mathrm{CD} 4^{+}$ $\mathrm{T}$ cell numbers in comparison to controls $(P=0.009$; Table 2).

\section{Discussion}

As in previous studies in Southeast Asia $[4,5]$ a large proportion of adults living in Timika have sub-microscopic infection with $P$. falciparum or $P$. vivax. In these individuals HLA-DR expression on total DC is retained. Similarly, the Treg cell phenotype, characterized by aTreg frequencies and rTreg-to-aTreg ratios, was comparable to that in uninfected adult controls. Collectively, the data indicate that neither DC nor Treg cells are phenotypically dysregulated by asymptomatic sub-microscopic Plasmodium infection. The absence of dysregulation suggests functional potential of these cells is maintained and may contribute to the control of infection and clinical immunity to Plasmodium infection.

The expression of HLA-DR is required by specialist antigen-presenting cells, such as DC, to present foreign antigen to $\mathrm{T}$ cells and is commonly used as a marker for DC activation/maturation. In controlled human Plasmodium infection studies, naïve volunteers experimentally infected with $P$. falciparum displayed reduced circulating $\mathrm{pDC}$ and $\mathrm{mDC}$ levels, followed by downregulation of HLA-DR on the surface of $\mathrm{pDC}$ [22] and $\mathrm{CD}_{1}{ }^{+} \mathrm{mDC}$ [23], all occurring at sub-microscopic PCR-level parasitaemia prior to development of patent parasitaemia. Conversely, in both sub-microscopic and patent asymptomatic infections in endemic area residents, the observation of unaltered HLA-DR expression on total circulating DC indicates that DC maturation is not reduced, which may contribute to the maintenance of asymptomatic infection. Comprehensive longitudinal studies in asymptomatic adults are required to fully characterize DC activation/function and to understand their stability and role in the maintenance of sub-microscopic and patent infection.

In contrast to DC activation, Treg cell activation may contribute to progression of disease by suppressing $\mathrm{T}$ cell responses and host immunity, favouring parasite growth $[20,21,28]$. CD $25{ }^{\text {hi }}$ CD $45 \mathrm{RA}^{-}$-activated Treg cells (aTreg) are highly suppressive and proliferative Treg cells [29], while $\mathrm{CD} 25^{+} \mathrm{CD} 45 \mathrm{RA}^{+}$-resting Treg cells (rTreg) provide a reservoir capable of subsequent activation. Adults with asymptomatic sub-microscopic $P$. falciparum or $P$. vivax infection showed neither a reduced nor an over-activated Treg cell response, characterized by aTreg frequencies and rTreg-to-aTreg ratios that were comparable to uninfected adult controls. This contrasted with the reduced Treg cell response characterized by a relative decrease in aTreg frequency and increase in rTreg-to-aTreg ratio in asymptomatic patent Plasmodium infection [14]. Furthermore, the data contrast with the more activated Treg cells observed in acute malaria [14, 20]. Therefore, in asymptomatic sub-microscopic infections, the data indicate that the CD45RA phenotype of Treg cells was not modulated and suggests the Treg cell compartment is phenotypically altered only by patent and not submicroscopic parasitaemia. This suggests maintenance of a normal, stably suppressive environment, allowing other immune cells to contribute to the control of infection.

Correlations between parasitaemia and Treg cells could not be examined since the degree of sub-microscopic

(See figure on next page.)

Fig. 2 Absolute number of $\mathbf{a} C D 303+$ plasmacytoid DC ( $\mathrm{pDC}$ ), b CD1c+ myeloid DC (mDC) and $\mathbf{c} C D 141+\mathrm{mDC}$ in peripheral blood of controls (a $\mathrm{n}=31, \mathbf{b} \mathrm{n}=35$ and $\mathbf{c} \mathrm{n}=25$ ), asymptomatic sub-microscopic P. falciparum (Pf) infection ( $\mathbf{a} n=6, \mathbf{b} n=6$ and $\mathbf{c} n=4)$, asymptomatic sub-microscopic P. vivax (Pv) infection (a $n=8, \mathbf{b} n=8$ and $\mathbf{c} n=8)$, asymptomatic patent P. falciparum infection $(\mathbf{a} n=14, \mathbf{b} n=17$ and $\mathbf{c} n=11)$, asymptomatic patent $P$. vivax infection $(\mathbf{a} n=17, \mathbf{b} n=19$ and $\mathbf{c} n=16)$, and adults with uncomplicated malaria (UM) $(\mathbf{a} n=4, \mathbf{b} n=8$ and $\mathbf{c} n=7)$. Graphs show median with interquartile range. "Kruskal-Wallis test with Dunn's multiple comparisons test or *Mann-Whitney $U$ test was used to compare between groups (*\# significantly different to controls). Data were obtained by analysis of fresh whole blood using 4-colour flow cytometry panels 

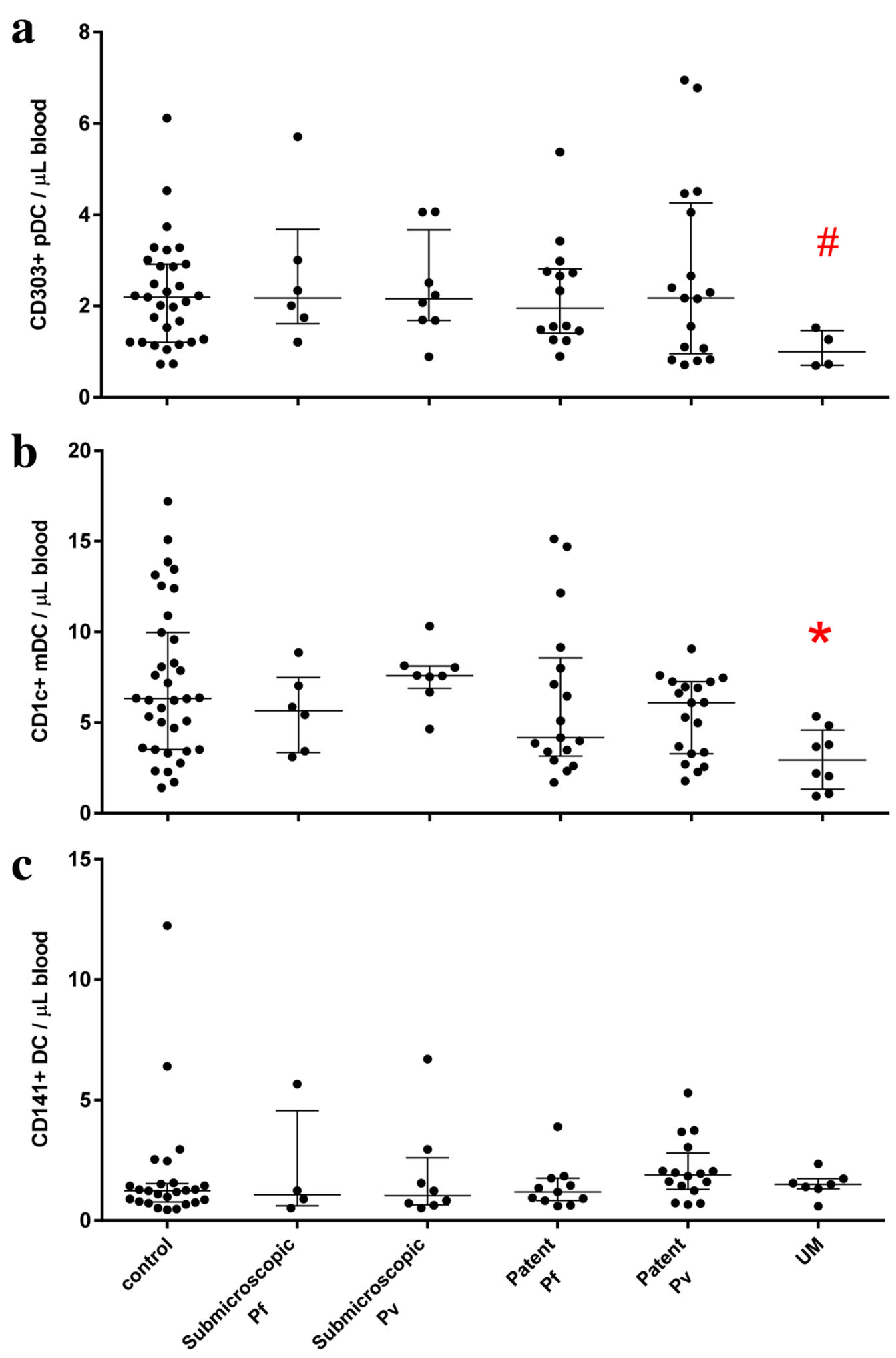
Table 2 T cell data

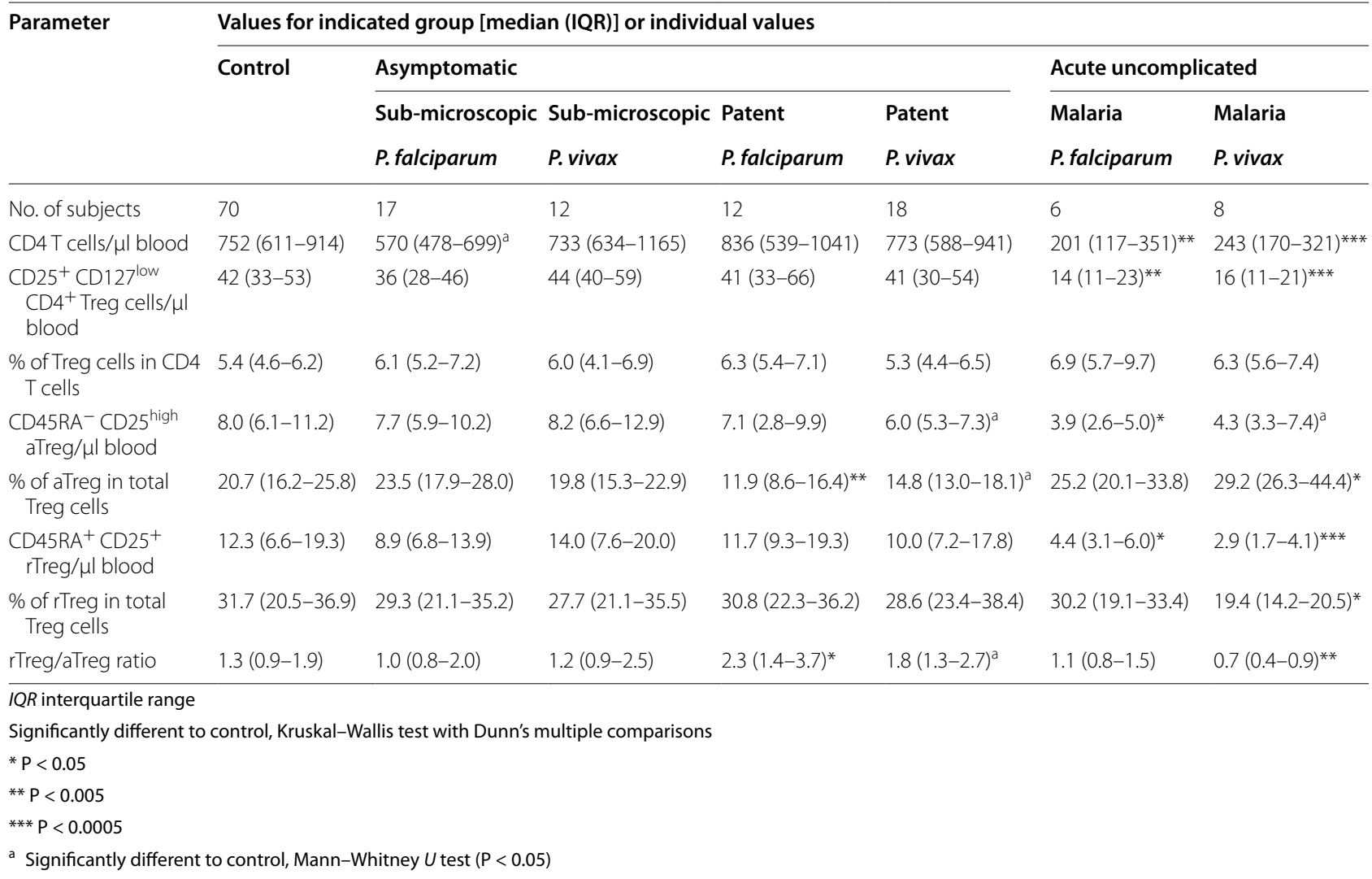

parasitaemia was not quantified. Boyle and colleagues [17] recently showed the loss of circulating Treg cells and down-regulation of TNFRII in Ugandan children highly exposed to malaria, which is thought to be implicated in the development of protective immunity to malaria. Additional studies are warranted to examine relationships between Treg cell activation and parasitaemia, including additional Treg cell activation markers (such as TNFRII, CTLA-4), and longitudinal assessment of Treg cell responses in asymptomatic carriers.

In sub-microscopic $P$. falciparum infection, peripheral lymphocytes and $\mathrm{CD} 4^{+} \mathrm{T}$ cells were reduced in asymptomatic adults, a finding similar to that observed in experimental sub-microscopic $P$. falciparum infection of naïve volunteers [22]. Despite this, no change in Treg cell frequency and numbers were found in endemic area residents with asymptomatic sub-microscopic $P$. falciparum or $P$. vivax infection, suggesting that stable Treg cells potentially minimize immune suppression and thereby support immune activation. Although asymptomatic adults with sub-microscopic $P$. falciparum infection were lymphopenic, their lymphocyte and $\mathrm{CD} 4^{+} \mathrm{T}$ cell counts were still significantly higher compared to adults with species-matched acute malaria.
The study had a number of limitations. As patent individuals were treated and sub-microscopic infections were only retrospectively identified, participants could not be longitudinally followed in this study, preventing the assessment of whether infected individuals remained asymptomatic, cleared the infection, or developed symptomatic malaria. It is also acknowledged that the sample sizes in the asymptomatic sub-microscopic groups with DC data were low due to poor sample quality and/or limitations in available blood volume. In addition, PCR was not performed on the sub-set of children in the original study [14] because finger-prick blood volumes were used for whole blood flow cytometry and this left insufficient or no blood for molecular analysis. Despite these limitations, modulations in DC and Treg cells clearly exist between controls, patent infection and acute malaria [14]. The current data indicate that sub-microscopic parasitaemia in endemic adults is not associated with variations in DC HLA-DR or Treg cell CD45RA expression.

\section{Conclusion}

The study provides no phenotypic evidence of DC and Treg cell dysregulation in asymptomatic sub-microscopic $P$. falciparum or P. vivax infection. DC in both 
sub-microscopic and patent infection expressed normal levels of HLA-DR; Treg cells exhibited reduced activation in patent infections and were unaltered in submicroscopic infections. The lack of apparent phenotypic dysregulation in DC and Treg cells identified in asymptomatic sub-microscopic Indonesian adults contrasts with the compromised DC induced by comparable PCR-level parasitaemia in experimental infection of malaria-naïve volunteers. The data extend the view that these immune cells may contribute to anti-parasitic immune mechanisms. Collectively, the findings suggest that malaria vaccines should aim to ensure appropriate DC and Treg cell responsiveness, a state observed in asymptomatic malaria-endemic area adults with sub-microscopic Plasmodium infection, but not found in adult volunteers experiencing first exposure to sub-microscopic Plasmodium infection.

\section{Additional files}

Additional file 1. List of antibody panels. The table provided represents the antibody panels used to characterize DC and Treg cells by flow cytometry.

Additional file 2. Representative staining of DC and $T$ cells in fresh whole blood from adults. The illustrations provided represent the flow cytometry gating strategy used to identify DC and Treg cells.

\section{Abbreviations}

DC: dendritic cells; Treg cells: regulatory T cells; HLA-DR: human leukocyte antigen (MHC class II); PCR: polymerase chain reaction; RBCs: red blood cells; pRBC: parasitized red blood cells; RSMM: Rumah Sakit Mitra Masyarakat; DNA: deoxyribonucleic acid; mDC: myeloid DC; pDC: plasmacytoid DC.

\section{Authors' contributions}

SK, TW, GM, KAP and NMA conceived and designed the study; SK, IH, KAP, RN $A K, F H B, E K, D A L$ and JRP carried out household survey and patient recruitment; SK performed field laboratory experiments; IH, ZP, RN, AK, JM and RNP performed and analysed PCR experiments: SK, TW and GM analysed flow cytometry data and statistics; SK, TW, GM, JM, RN, NMA, CRE, JRP and RNP: intellectual contribution and preparation of manuscript. All authors read and approved the final manuscript.

\section{Author details \\ ${ }^{1}$ Global and Tropical Health Division, Menzies School of Health Research and Charles Darwin University, Darwin, Australia. ${ }^{2}$ Eijkman Institute for Molec- ular Biology, Jakarta, Indonesia. ${ }^{3}$ Timika Malaria Research Programme, Papuan Health and Community Development Foundation, Timika, Papua, Indonesia. ${ }^{4}$ Rumah Sakit Umum Daerah Kabupaten Mimika, Timika, Papua, Indonesia. ${ }^{5}$ QIMR Berghofer Medical Research Institute, Brisbane, Australia. ${ }^{6}$ Department of Paediatrics, University of Gadjah Mada, Yogyakarta, Indonesia. ${ }^{7}$ Nuffield Department of Medicine, Centre for Tropical Medicine and Global Health, University of Oxford, Oxford, UK.}

\section{Acknowledgements}

We thank the participants in the household survey; field and laboratory staff for acquiring samples; Ferryanto Chalfein and Pak Prayoga for their microscopy expertise; Dr. Leily Trianty, Dr. Ella Curry and Grennady Wirjanata for their support in the laboratory and assistance with logistics; RSMM hospital for use of the haematological analyzer; and, Prof. Yati Soenarto, Dr. Yodi Mahendradhata and Dr. Franciscus Thio for facilitation of this study.
This study was funded by the National Health and Medical Research Council of Australia (Project Grants 1021198, 1021121, Program Grant 1037304 and fellowships to NMA, CE and GM). The fieldwork was funded by Wellcome Trust (Senior Fellowship in Clinical Science to RNP 091625 and Training Fellowship to JRP 062058). The funding bodies had no input in the design, collection, analysis or interpretation of data, and the writing or submission of the manuscript for publication.

\section{Competing interests}

The authors declare that they have no competing interests.

Received: 9 March 2016 Accepted: 10 June 2016

Published online: 21 June 2016

\section{References}

1. Doolan DL, Dobaño C, Baird JK. Acquired immunity to malaria. Clin Microbiol Rev. 2009;22:13-36.

2. Boutlis CS, Yeo TW, Anstey NM. Malaria tolerance-for whom the cell tolls? Trends Parasitol. 2006;22:371-7.

3. Imwong M, Stepniewska K, Tripura R, Peto TJ, Lwin KM, Vihokhern B, et al. Numerical distributions of parasite densities during asymptomatic malaria. J Infect Dis. 2016;213:1322-9.

4. Imwong M, Nguyen T, Tripura R, Peto T, Lee S, Lwin K, et al. The epidemiology of subclinical malaria infections in South-East Asia: findings from cross-sectional surveys in Thailand-Myanmar border areas, Cambodia, and Vietnam. Malar J. 2015;14:381.

5. Kaisar M, Supali T, Wiria A, Hamid F, Wammes L, Sartono E, et al. Epidemiology of Plasmodium infections in Flores Island, Indonesia using real-time PCR. Malar J. 2013;12:169.

6. Bottius E, Guanzirolli A, Trape J-F, Rogier C, Konate L, Druilhe P. Malaria: even more chronic in nature than previously thought; evidence for subpatent parasitaemia detectable by the polymerase chain reaction. Trans $\mathrm{R}$ Soc Trop Med Hyg. 1996;90:15-9.

7. May J, Mockenhaupt FP, Ademowo OG, Falusi AG, Olumese PE, Bienzle U, et al. High rate of mixed and subpatent malarial infections in southwest Nigeria. Am J Trop Med Hyg. 1999;61:339-43.

8. Roper C, Elhassan IM, Hviid L, Giha H, Richardson W, Babiker H, et al. Detection of very low level Plasmodium falciparum infections using the nested polymerase chain reaction and a reassessment of the epidemiology of unstable malaria in Sudan. Am J Trop Med Hyg. 1996;54:325-31.

9. Bousema T, Okell L, Felger I, Drakeley C. Asymptomatic malaria infections: detectability, transmissibility and public health relevance. Nat Rev Microbiol. 2014;12:833-40.

10. Imwong M, Hanchana S, Malleret B, Rénia L, Day NPJ, Dondorp A, et al. High-throughput ultrasensitive molecular techniques for quantifying low-density malaria parasitemias. J Clin Microbiol. 2014;52:3303-9.

11. Hofmann N, Mwingira F, Shekalaghe S, Robinson LJ, Mueller I, Felger I. Ultra-sensitive detection of Plasmodium falciparum by amplification of multi-copy subtelomeric targets. PLoS Med. 2015;12:e1001788.

12. Adams M, Joshi S, Mbambo G, Mu A, Roemmich S, Shrestha B, et al. An ultrasensitive reverse transcription polymerase chain reaction assay to detect asymptomatic low-density Plasmodium falciparum and Plasmodium vivax infections in small volume blood samples. Malar J. 2015;14:520.

13. Okell LC, Bousema T, Griffin JT, Ouédraogo AL, Ghani AC, Drakeley CJ. Factors determining the occurrence of submicroscopic malaria infections and their relevance for control. Nat Commun. 2012;3:1237.

14. Kho S, Marfurt J, Noviyanti R, Kusuma A, Piera KA, Burdam FH, et al. Preserved dendritic cell HLA-DR expression and reduced regulatory $T$ cell activation in asymptomatic Plasmodium falciparum and P. vivax infection. Infect Immun. 2015;83:3224-32.

15. Wammes LJ, Wiria AE, Toenhake CG, Hamid F, Liu KY, Suryani H, et al. Asymptomatic plasmodial infection is associated with increased tumor necrosis factor receptor $\|$-expressing regulatory $T$ cells and suppressed type 2 immune responses. J Infect Dis. 2013;207:1590-9.

16. Portugal S, Moebius J, Skinner J, Doumbo S, Doumtabe D, Kone Y, et al. Exposure-dependent control of malaria-induced inflammation in children. PLoS Pathog. 2014;10:e1004079. 
17. Boyle MJ, Jagannathan P, Farrington LA, Eccles-James I, Wamala S, Mclntyre TI, et al. Decline of FoxP3 + regulatory CD4 T cells in peripheral blood of children heavily exposed to malaria. PLoS Pathog. 2015;11:e1005041.

18. Pinzon-Charry A, Woodberry T, Kienzle V, McPhun V, Minigo G, Lampah DA, et al. Apoptosis and dysfunction of blood dendritic cells in patients with falciparum and vivax malaria. J Exp Med. 2013;210:1635-46.

19. Urban BC, Mwangi T, Ross A, Kinyanjui S, Mosobo M, Kai O, et al. Peripheral blood dendritic cells in children with acute Plasmodium falciparum malaria. Blood. 2001;98:2859-61.

20. Minigo G, Woodberry T, Piera KA, Salwati E, Tjitra E, Kenangalem E, et al. Parasite-dependent expansion of TNF receptor II-positive regulatory $T$ cells with enhanced suppressive activity in adults with severe malaria. PLoS Pathog. 2009;5:e1000402.

21. Walther $\mathrm{M}$, Tongren JE, Andrews $\mathrm{L}$, Korbel $\mathrm{D}$, King $\mathrm{E}$, Fletcher $\mathrm{H}$, et al. Upregulation of TGF- $\beta$, FOXP3, and CD4+CD25+ regulatory T cells correlates with more rapid parasite growth in human malaria infection. Immunity. 2005;23:287-96.

22. Woodberry T, Minigo G, Piera KA, Amante FH, Pinzon-Charry A, Good MF, et al. Low-level Plasmodium falciparum blood-stage infection causes dendritic cell apoptosis and dysfunction in healthy volunteers. J Infect Dis. 2012;206:333-40.

23. Loughland JR, Minigo G, Burel J, Tipping PE, Piera KA, Amante FH, et al. Profoundly reduced CD1C+ myeloid dendritic cell HLA-DR and CD86 expression and increased TNF production in experimental human bloodstage malaria infection. Infect Immun. 2016;84(5):1403-12.
24. Karyana M, Burdarm L, Yeung S, Kenangalem E, Wariker N, Maristela R, et al. Malaria morbidity in Papua Indonesia, an area with multidrug resistant Plasmodium vivax and Plasmodium falciparum. Malar J. 2008;7:148.

25. Singh B, Bobogare A, Cox-Singh J, Snounou G, Abdullah MS, Rahman HA. A genus- and species-specific nested polymerase chain reaction malaria detection assay for epidemiologic studies. Am J Trop Med Hyg. 1999;60:687-92.

26. McCarthy JS, Sekuloski S, Griffin PM, Elliott S, Douglas N, Peatey C, et al. A pilot randomised trial of induced blood-stage Plasmodium falciparum infections in healthy volunteers for testing efficacy of new antimalarial drugs. PLoS One. 2011;6:e21914.

27. Tham JM, Lee SH, Tan TMC, Ting RCY, Kara UAK. Detection and species determination of malaria parasites by PCR: comparison with microscopy and with ParaSight-F and ICT malaria Pf tests in a clinical environment. J Clin Microbiol. 1999;37:1269-73.

28. Abel S, Lückheide N, Westendorf AM, Geffers R, Roers A, Müller W, et al. Strong impact of CD4+Foxp3+ regulatory $T$ cells and limited effect of T cell-derived IL-10 on pathogen clearance during Plasmodium yoelii infection. J Immunol. 2012;188:5467-77.

29. Miyara M, Yoshioka Y, Kitoh A, Shima T, Wing K, Niwa A, et al. Functional delineation and differentiation dynamics of human CD4+ T cells expressing the FoxP3 transcription factor. Immunity. 2009;30:899-911.

\section{Submit your next manuscript to BioMed Central and we will help you at every step:}

- We accept pre-submission inquiries

- Our selector tool helps you to find the most relevant journal

- We provide round the clock customer support

- Convenient online submission

- Thorough peer review

- Inclusion in PubMed and all major indexing services

- Maximum visibility for your research

Submit your manuscript at www.biomedcentral.com/submit 